\title{
VOLVULUS IN A THREE-WEEKS-OLD BABY WITH A MECKEL'S DIVERTICULUM AND CONGENITAL MORBUS CORDIS
}

\author{
BY
}

\author{
WILFRID F. GAISFORD, M.D., F.R.C.P. \\ Physician, Dudley Road Hospital, Birmingham
}

Volvulus is a comparatively rare occurrence in childhood and in infancy is of extreme rarity. Occasional cases of foetal volvulus have been described, due to extension of the normal umbilical cord torsion to the intestine, to anomalies of the mesenteric attachment, to fixation of the bowel through a Meckel's diverticulum, or through peritoneal bands. It may be a terminal phenomenon in congenital atresia of the bowel, and in one such case described by Saxl in 1930, the infant was born alive and developed characteristic signs and symptoms of obstruction on the second day of life. At autopsy there was found a volvulus, due to congenital atresia of the ileum and to a common mesentery, and also a band between the gall bladder and the appendix. In addition the infant had a congenital cardiac lesion, a patent ductus arteriosus.

\section{Case report}

The case here recorded was a female infant, the ninth child of a mother aged forty-three, born prematurely by breech presentation, and weighing $4 \mathrm{lb} .7 \mathrm{oz}$. She had mongoloid features but otherwise appeared a normal thirty-three weeks gestation baby. The cord separated on the sixth day, at which time she weighed $4 \mathrm{lb}$. Because of the failure of the mother's milk she was given feeds of lactic acid milk with 10 per cent. glucose, one ounce two hourly, and on this formula she did well, regaining her birth weight by the twentieth day. Ext. thyroid sicc. $\frac{1}{10}$ grain, b.d., was added from the tenth day. She had occasional attacks of cyanosis, thought to be due to atelectasis, which responded to carbon dioxide and oxygen. The heart sounds were normal. There was no vomiting, and the stools were normal.

On the twenty-first day, fever (T. $104^{\circ} \mathrm{F}$.) and dyspnoea developed and she presented the picture of broncho-pneumonia, with scattered patches of bronchial breathing over both bases.

The next day she became rapidly worse and died. About three hours before death she manifested symptoms of shock and sudden collapse, and her abdomen distended, but there was no vomiting, and her stools remained normal.

Post-mortem examination was made by Dr. W. Whitelaw, the hospital pathologist, seven hours after death, and his report was as follows :- 
The body of a premature female infant, with mongoloid facies, and markedly protuberant abdomen. Weight $4 \mathrm{lb} .9 \mathrm{oz}$.

THORAX. The heart is enlarged and there is a wide defect in the interventricular septum. The aortic and pulmonary vessels are normal, the ductus arteriosus closed and the foramen ovale well valved.

The lungs show scattered areas of atelectasis at both bases but no broncho-pneumonia.

ABDomen. On opening the abdomen a small quantity of bloodstained fluid is noticed. The small bowel is distended to a distance about twelve inches above the caecum at which point a volvulus has occurred. The bowel between this point (which shows the presence of a Meckel's diverticulum, free from any adhesions or fixation, about half an inch in diameter) and the ileocaecal valve, is plum-coloured and contains blood. The twist of the strangulated bowel is a half turn counter-clockwise. The mesentery is unusually long, but otherwise normal. The peritoneal coat over the affected bowel still retains its lustre, pointing to the very recent onset of the obstruction. The appendix and caecum are unaltered, and the large bowel contains normal faeces. The stomach and duodenum are normal.

The following points are of interest :-

1. The only sign of volvulus was the sudden abdominal distension. There was no vomiting and the stools were normal.

2. Apart from a long mesentery, the only causative factor of the volvulus found was a Meckel's diverticulum, yet this was quite free from any fixation.

3. Congenital morbus cordis is a frequent finding in mongols ; although this infant was the ninth child of an elderly mother she had no other signs of mongolism except the facies.

Saxl's case, referred to above, which was not a mongol, also had a congenital cardiac lesion.

Thanks are due to Dr. T. M. Anderson, Medical Superintendent of the Hospital, for permission to publish this case, and to Dr. Whitelaw for the postmortem findings.

\section{REFERENCE}

Saxl, N. J. (1930). Amer. Med., 36, 706. 